\title{
Defining physical quantities for upper secondary school students
}

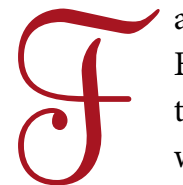

amiliarity breeds contempt, or so the old English saying goes. Complacency rather than contempt might be a better word for what we have in mind, but ironically semantic accuracy would not in this case convey nearly so well our intended meaning. We are concerned with the definitions of physical quantities, such as weight and electric field, for which accuracy is crucial. Physics education research has shown how easy it is for students to develop incorrect conceptions. Take Newton's third law of motion for example. Although it is not a physical quantity, students' difficulties with this law are well known and illustrate just how easy it is for students to misunderstand a basic idea through loose terminology. The classical form of the law, to every action there is an equal and opposite reaction, can easily be transformed into, for every force there is an equal and opposite force. Far from enlightening students, this can very easily, and often does, lead to the misconception that in simple mechanical systems dissipative forces, such as friction or air resistance, will inevitably increase until there is no nett force acting. The choice of words and phrasing is crucial in shaping our thoughts and complacency is the enemy of precision.

Many professional physicists will use ideas like weight or electric field without ever stopping to think about their precise definitions. Imagine, though, that you are a teacher looking to find the correct definition to convey to your students. It might be that you are familiar with the ideas but want to brush up on your basic knowledge or, as is occurring increasingly across much of Europe, if physics is not your specialty but you are still tasked with teaching it, you might be looking for either insight or knowledge you don't currently possess. You have access to untold quantities of information and it is very unlikely you will find a single definition. How do you know which to choose?

You could always look for an authoritative source and instinctively you might turn to a text book. After all, psychologists tell us that an essential component of reasoning is access to usable knowledge, so surely it must follow that if school students are to learn to think and reason correctly about physics at school then surely what they are told must be correct? This might indeed be the ideal, but at least in the UK, if not elsewhere in Europe, things are a little more complicated. In the UK there are five awarding organisations (AO) that administer A-level examinations and the qualifications derived from them. Each publishes its own resources, complete with its own set of definitions. A teacher might naturally stick to the resources from the particular $\mathrm{AO}$ administering the exams his or her students will be taking and whilst that might suit an individual teacher, it means that school students up and down the country are being taught different things according to where they live and whose examination they are taking.

This wouldn't be so bad if all the different definitions of a given quantity were equivalent, but, whether a definition is actively misleading or simply open to mis-interpretation, there is no mechanism of oversight and nothing to guarantee that intended and actual meanings converge. This is the situation that an interested group of people at the Institute of Physics, led by the then Director of Education, Prof. Peter Main, and working with the National Physical Laboratory, set out to address by constructing a glossary of physical quantities for use with 16-19 year-olds. The glossary currently consists of 34 definitions, both in print and on the web ${ }^{1}$, with a similar number to be added to the website in the near future.

For consistency and clarity, the definitions all have the same structure. They start with a description and a discussion followed by the units, first the SI units, then their expression in terms of SI base units and, if relevant, other frequently used units. The common mathematical expressions then follow, though if necessary mathematical definitions are given earlier. Related entries in the glossary are then listed and finally the definition is put into some kind of context. For magnetic field, for example, the relative strengths of several different fields, including the Earth's magnetic field and the field in a MRI scanner, are described.

Many of the descriptions and discussions are augmented by simple diagrams that convey the essential concept.

${ }^{1}$ https://spark.iop.org/collections/glossary\#gref 
The figure below shows the diagram associated with stress and illustrates the importance of ratio of applied force to area rather than total force. The mass of a person wearing a stiletto high-heeled shoe is likely to be around 50kg, give or take, whereas a for full-grown elephant the mass could be anything between $3500 \mathrm{~kg}$ and $6500 \mathrm{~kg}$, depending on its sex and whether Indian or African. However, the cross-sectional area through which the weight is transmitted is likely to differ by a factor of many thousands, meaning that the stress beneath the foot of an elephant is less than the stress beneath a stiletto heel. This is depicted by the lighter shading associated with the former compared with the latter.

Having a set of authoritative definitions such as these in a single accessible place has obvious advantages, not least for supporting teachers who are not specialists in physics and the Physics Education Division of the EPS is working with the IOP to promote the use of the glossary across Europe. The glossary is free to use as it is by anyone, not just teachers in the UK. For those wanting to edit or amend it, for example by translating it into a European language, the IOP is in the process of developing a franchise model which we anticipate will be available in the spring of 2020. Whilst we will be happy to accommodate individual teachers, we are particularly keen to make contact with those responsible for school curricula and assessments in different countries across Europe. Any readers around Europe who are interested in either using a franchised version of the glossary or are able to put us in contact with appropriate organisations within their own countries are asked to contact David Sands ond.sands@hull.ac.uk.

\section{About the Authors}

Daniel Heanes is Accreditation Officer at the Institute of Physics. In his previous role as Higher Education and Curriculum Officer he acted as editor and secretary to the working group for the IOP/NPL Glossary of Physics Quantities during the last three years of its development for the UK education context.

David Sands is currently chair of the Physics Education Division of the EPS. Presently at the University of Hull, he has specialised in various aspects of physics education and, in particular, concepts and conceptual understanding. His current research is focussed on the cognitive foundations of learning and teaching in physics

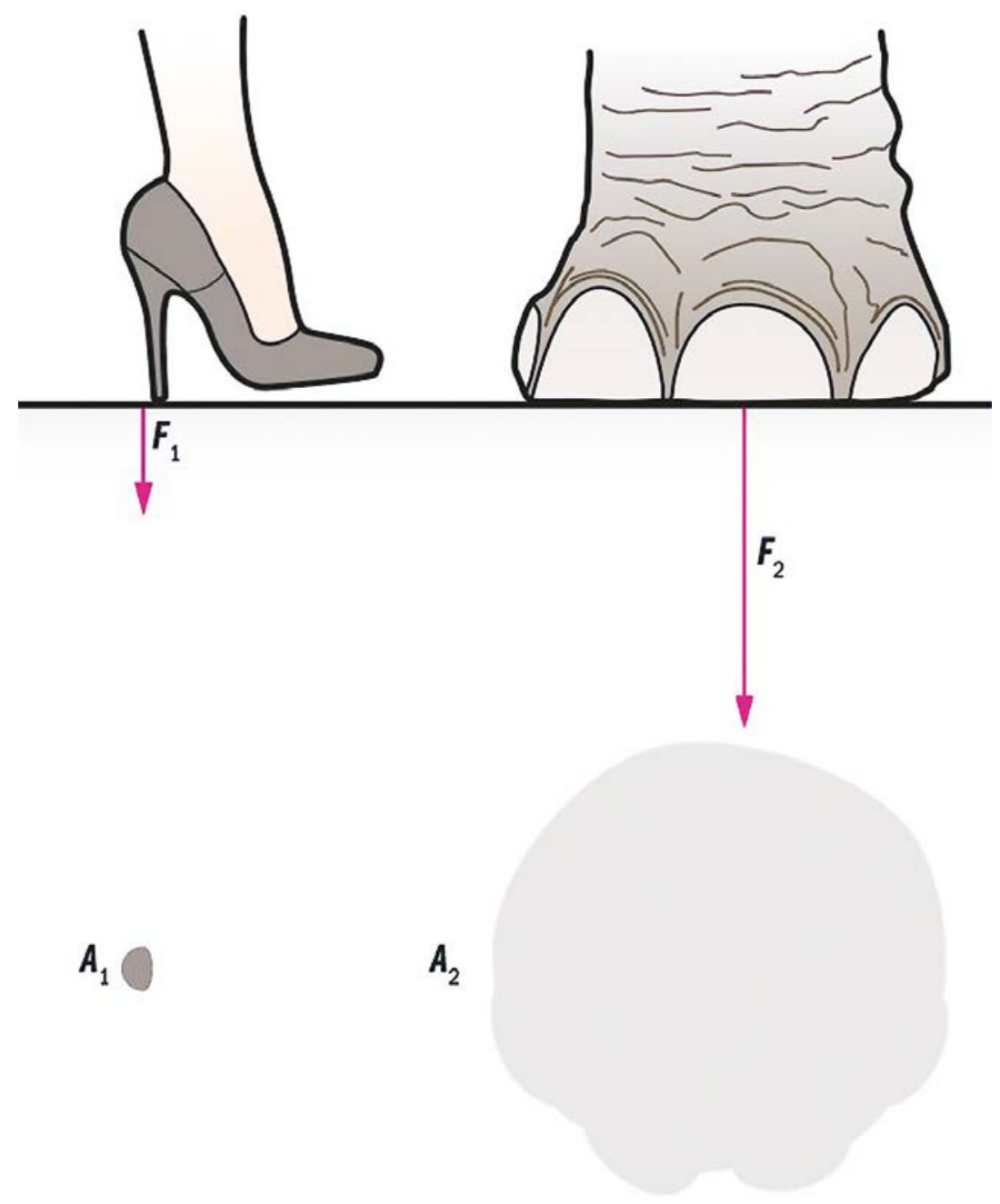

